\title{
REVIEW ARTICLE \\ Why is breastfeeding a risk factor for HIV-1 transmission despite HIV-1- infected mothers receiving combination ART (cART)?
}

\author{
Anuttara Bhadra ${ }^{1}$ \\ ${ }^{1}$ Medical student, University of Liverpool \\ Correspondence: anuttarabhadra@yahoo.co.uk
}

\begin{abstract}
Mother-to-child transmission (MTCT) of human immunodeficiency virus type 1 (HIV-1) is an important source of HIV-1 infection in infants, and can occur at any point, including in utero, at the time of delivery, and via breastfeeding. In the absence of intervention, such as the use of antiretroviral therapy (ART), MTCT of HIV-1 during pregnancy or delivery can affect approximately $15-25 \%$ of infants, with a further $5-20 \%$ of infants becoming infected postnatally during breastfeeding. The use of maternal ART while breastfeeding reduces the MTCT risk from $35 \%$ without any intervention to less than $5 \%$. Although a significant improvement, $5 \%$ of infants continue to be infected.' Maternal factors that contribute to this continued risk of transmission despite taking ART include the method of feeding, breast health, RNA and DNA viral load in breast milk and plasma, and maternal nutrition. Infant factors such as the disruption in the integrity of the gastrointestinal mucosal surfaces also contribute to an increased rate of MTCT.
\end{abstract}

Aims: This literature review aimed to investigate why breastfeeding is still a risk factor despite HIV-1-infected mothers being on effective combination ART (cART)? This review will explore the associated factors that contribute to the increased risk of HIV-1 transmission to the infant via breastfeeding.

Copyright Royal Medical Society. The copyright is retained by the author and the Royal Medical Society, except where explicitly otherwise stated. Scans have been produced by the Digital Imaging Unit at Edinburgh University Library. Res Medica is supported by the University of Edinburgh's Journal Hosting Service: http://journals.ed.ac.uk

ISSN: 2051-7580 (Online) ISBN: 0482-3206 (Print)

Res Medica is published by the Royal Medical Society, 5/5 Bristo Square, Edinburgh, EH8 9AL

Res Medica, 2015, 23(1):29-37.

doi:10.2218/resmedica.v23i1.1239 


\section{Introduction}

Breastfeeding is recognized for its effective role in significantly decreasing the risk of childhood morbidity, which includes gastrointestinal and respiratory infections. ${ }^{2}$ The World Health Organization (WHO) recommends that, on a population basis, infants should be breastfed exclusively for the first 6 months of life for optimal health benefits. ${ }^{3}$ However, despite these significant benefits, breastfeeding serves as a possible route for HIV-infected mothers to transmit HIV to their infants.

${ }^{4}$ Without intervention, HIV-infected mothers will transmit their infection to their infants during pregnancy or delivery in approximately $15-25 \%$ of cases, with a further $5-20 \%$ of infants becoming infected postnatally during breastfeeding, resulting in an overall risk of $30-45 \%$. At the end of 2011, approximately 3.4 million children were infected with HIV, with $91 \%$ living in sub-Saharan Africa. ${ }^{4}$ Therefore, reducing МTCT while maximizing the benefits of breastfeeding is evidently a public health dilemma, and addressing this has the potential to save many lives.

The main risk factors for postnatal transmission through breastfeeding relate to the control of HIV virus replication in maternal blood or breast milk. Maternal CD4 cell count, different HIV strains, RNA viral load in maternal plasma and breast milk, and breast pathologies such as mastitis are all strongly associated with an increased risk of transmission. ${ }^{5}$ Furthermore, the type of feeding provided to the infant can have an impact on the transmission. The 2013 WHO principles and recommendations and the Center for Disease Control and Prevention (CDC) have published recommendations on HIV and infant feeding stratified according to income. For mothers in low- and middle-income countries, the $\mathrm{WHO}$ recommended that, in the absence of antiretroviral therapy (ART), breastfeeding should be implemented for the "first 6 months of life unless replacement feeding is acceptable, feasible, affordable, sustainable and safe for them and their infants". ${ }^{3}$ Additionally, breastfeeding should be continued when ART treatment has commenced. In contrast, the CDC recommended that HIV-1infected women in high-income countries should refrain from breastfeeding and provide safe replacement feeding, even when taking ART. ${ }^{6}$ Exclusive breastfeeding for 6 months has been associated with a threefold decreased risk of MTCT of HIV-1 when compared with non-exclusive (mixed feeding or non-exclusive breastfeeding). ${ }^{5}$ Therefore, promoting and encouraging the most appropriate feeding will help control and minimize this important risk factor.

WHO policy calls for universal access to ART in pregnant and breastfeeding mothers, but in fact, WHO reports suggest that in the African region, only $63 \%$ of individuals eligible for treatment were actually able to access it in 2012. ${ }^{7}$ In low-resource settings, women should be encouraged to breastfeed unless their individual circumstances enable a regular and sufficient supply of formula milk for exclusive use and facilities for sterile preparation; this tends to be an exception. While the most successful strategy to eliminate postnatal HIV transmission would be the complete avoidance of exposure to breast milk, increased infant morbidity and mortality has been associated with the use of infant formula where there is a lack of clean water and proper hygiene in formula preparation.

The prevention of mother-to-child transmission of HIV (PMTCT) is one of the most pressing public health concerns and, despite the use of interventions including ART, there is still a risk that the infection will successfully pass onto the infant. It is thought that the MTCT rate for women taking combined ART (CART) while breastfeeding reduces from $35 \%$ in the untreated population to less than $5 \% .{ }^{1,8}$ Given that an estimated 1.5 million HIVpositive women become pregnant annually, this figure is appreciable. This review seeks to describe reasons for continued infection risk to the breastfed infant despite effective cART and the arising clinical and research implications.

\section{Methodology}

An initial discussion and literature review focused the physiology of HIV-1 replication in maternal blood or breast milk. Noting the limited number of papers on HIV-1 replication and the effect on MTCT, a question was formed to explore the reasons for MTCT of HIV-1 focusing on HIV-1 replication in breast milk and plasma. The following databases were used to identify appropriate studies: MEDLINE, Google Scholar, and Scopus. Electronic journals, such as the British Medical Journal (BMJ), the Lancet, and Journal of the American Medical Association were also used. The search terms used are outlined in Table 1. 


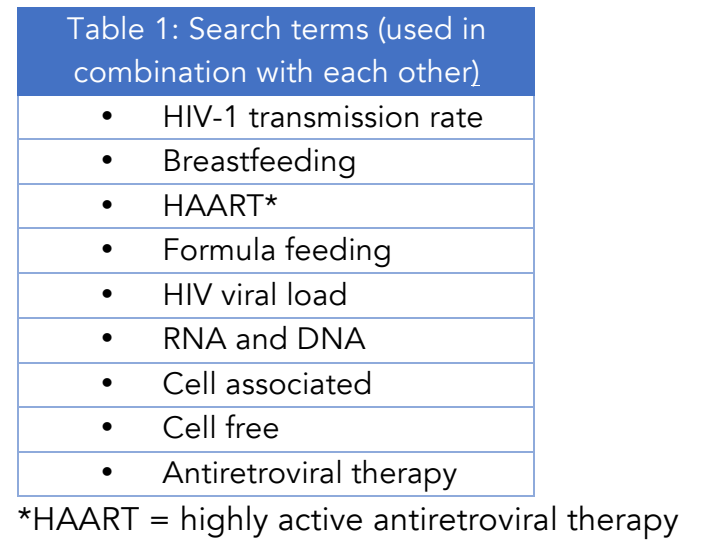

After having searched the specific terms on the various databases, few relevant studies were found; most focused on MTCT rates among breastfeeding HIV-1-infected mothers. A limitation was that the outcome measure, i.e. cumulative transmission rate, was not present in all studies, which made comparison between studies difficult. Four eligible studies, with a focus on the effect of breastfeeding on HIV transmission rate, were evaluated and reviewed. The studies also explored the cumulative MTCT of HIV-1 in breastfeeding and formulafeeding infants, and a further eight compared different ART regiments in preventing HIV transmission during breastfeeding. The data from these eight studies was summarized by one review paper, which compared the cumulative transmission rates between different regimens of ART used. The data was then evaluated in this review and the reasons for the presence of transmission rates in spite of ART were explored.

\section{HIV transmission through breastfeeding}

Several observational studies and randomized controlled trials (RCTs) have investigated the effectiveness of maternal ART in the reduction of MTCT rates of HIV-1 in infants who were breastfed. Results from Table 1 show that maternal triple ART prophylaxis does effectively reduce MTCT in comparison with no ART (as seen in Table 2); however, MTCT rates still exist and continue to increase from 4 weeks to 24 months. Findings from these studies also indicate the effectiveness of infant ART prophylaxis in reducing postnatal HIV transmission during breastfeeding. Studies that give a combination of infant short-dose nevirapine plus zidovudine (sdNVP+ZDV) for 7 days, have a higher reduction in the MTCT rate than those who give only infant sdNVP or ZDV with 3TC.

\section{Ndauti et al. 2000}

A RCT conducted in Kenya (Ndauti et al. 2000), consisted of 425 antiretroviral-naïve women, of whom 212 were randomly assigned to breastfeed their infants and 213 to use formula feeding. ${ }^{16}$ The results showed that the cumulative HIV-1 infection rate at 24 months was $36.7 \%$ in the breastfeeding group and $20.5 \%$ in the formula-feeding group. ${ }^{16}$ Moreover, the breastfeeding group was associated with a significantly lower HIV-1-free survival rate as, at 2 years, the rate of HIV-1-free survival was $58.0 \%$ in the breastfeeding group versus $70.0 \%$ in the formula group ( $p=0.02$ ). An important aspect to consider in this and all other trials that investigate the risk of HIV-1 transmission with breastfeeding is compliance with the feeding modalities that were assigned to the mothers. Reported compliance was $96.0 \%$ in the breastfeeding group and $70 \%$ in the formula-feeding group (defined as "complete avoidance of breast milk"). This may limit interpretation of results, since compliance is usually self-reported and is a difficult factor to control. ${ }^{16}$

\section{Thior et al. 2006}

In contrast, Thior et al. 2006 ${ }^{17}$ undertook a RCT among 1200 women to investigate the difference in efficacy in reducing postnatal MTCT of HIV between breastfeeding and infant ZDV prophylaxis for 6 months and formula-feeding with 1-month-old infant ZDV prophylaxis. The results of this trial showed that the cumulative HIV-1 infection rate at 18 months was higher in breastfed children than in the formula-fed children despite the addition of 6 months of ZDV prophylaxis; cumulative HIV-1 infection rate 9.5\% and $6.0 \%$, respectively yielding $p=0.02$. However, compliance was an issue as full adherence to formula feeding and exclusive breastfeeding was reported at $93.0 \%$ and $57.1 \%$ at month 18 and 6, respectively. Similarly to Ndauti et al. 2000, there were significantly higher mortality rates in the formulafeeding group than the breast fed group, especially in the first 7 months, mainly due to diarrhoeal disease. The cumulative death rate in the formulafed group was $9.3 \%$ compared with $4.9 \%$ in the breastfed group, with a $4.4 \%$ mortality rate difference, which halved by 18 months. ${ }^{17}$ 
Table 1. Comparison of the effect of maternal ART prophylaxis (postpartum) on MTCT rates of HIV-1 on breastfed infants

\begin{tabular}{|c|c|c|c|c|c|c|c|c|c|c|c|}
\hline \multirow[t]{3}{*}{ Study } & \multirow[t]{3}{*}{ Country } & \multirow[t]{3}{*}{ Type of trial } & \multirow{3}{*}{$\begin{array}{l}\text { Maternal } \\
\text { ART regimen }\end{array}$} & \multirow{3}{*}{$\begin{array}{l}\text { Infant ART } \\
\text { regimen }\end{array}$} & \multicolumn{7}{|c|}{ Cumulative HIV-1 infection rate (\%) } \\
\hline & & & & & \multirow[t]{2}{*}{ At birth } & \multirow[t]{2}{*}{4 weeks } & \multirow[t]{2}{*}{6 weeks } & \multicolumn{4}{|c|}{ Months } \\
\hline & & & & & & & & 6 & 9 & 12 & 24 \\
\hline $\begin{array}{l}\text { DREAM (Palombi et al. } \\
\text { 2007) Error! Bookmark not defined. }\end{array}$ & $\begin{array}{l}\text { Mozam- } \\
\text { bique }\end{array}$ & Observational & Triple ART & $\begin{array}{l}\text { sdNVP+ZDV for } \\
7 \text { days }\end{array}$ & --- & 1.2 & & 2.2 & --- & --- & --- \\
\hline KiBS (Thomas et al. 2011) & Kenya & Observational & Triple ART & sdNVP & 2.5 & --- & 4.2 & 5 & --- & 5.7 & 7 \\
\hline $\begin{array}{l}\text { MITRA PLUS (Kilewo et al. } \\
\text { 2009) }{ }^{11}\end{array}$ & Tanzania & Observational & Triple ART & $\begin{array}{l}\text { ZDV+3TC for } 7 \\
\text { days }\end{array}$ & --- & --- & 4.1 & 5 & --- & --- & --- \\
\hline $\begin{array}{l}\text { Amata (Peltier et al. } \\
2009)^{12}\end{array}$ & Rwanda & Observational & Triple ART & $\begin{array}{l}\text { sdNVP+ZDV for } \\
7 \text { days }\end{array}$ & 1.3 & --- & 1.3 & --- & 1.8 & --- & --- \\
\hline $\begin{array}{l}\text { Kesho Boro (Kesho Boro } \\
\text { et al. 2011) }\end{array}$ & Kenya & $\mathrm{RCT}$ & Triple ART & $\begin{array}{l}\text { sdNVP+ZDV for } \\
7 \text { days }\end{array}$ & 1.8 & --- & 3.3 & 4.9 & --- & 5.4 & --- \\
\hline $\begin{array}{l}\text { Mma Bana (Shapiro et al. } \\
2010)^{14}\end{array}$ & Botswana & $\mathrm{RCT}$ & $\begin{array}{l}\text { ZDV/3TC/ } \\
\mathrm{LPV} / \mathrm{r}\end{array}$ & $\begin{array}{l}\text { sdNVP+ZDV for } \\
4 \text { weeks }\end{array}$ & --- & --- & 1.1 & --- & -- & --- & --- \\
\hline $\begin{array}{l}\text { Bana (Shapiro et al. } \\
2010)^{14}\end{array}$ & Botswana & $\mathrm{RCT}$ & $\begin{array}{l}\text { ZDV/3TC/ } \\
A B C\end{array}$ & $\begin{array}{l}\text { sdNVP+ZDV for } \\
4 \text { weeks }\end{array}$ & --- & --- & 1.1 & --- & --- & --- & --- \\
\hline $\begin{array}{l}\text { BAN (Jamieson et al. } \\
2012)^{15}\end{array}$ & Malawi & RCT & Triple ART & $\begin{array}{l}\text { sdNVP+ZDV for } \\
7 \text { days }\end{array}$ & --- & --- & 2.9 & --- & 4 & --- & --- \\
\hline
\end{tabular}

KEY:

$A R T=$ antiretroviral therapy, HIV-1 = human immunodeficiency virus type 1, RCT = randomized control trial, sdNVP = short-dose nevirapine, $Z$ DVV $=$ zidovudine, $3 T C=$ lamivudine, $\mathrm{LPV} / \mathrm{r}=$ lopinavir and ritonavir, $\mathrm{ABC}=$ abacavir 
Table 2. Comparison of MTCT rates of HIV-1 for infants between the breastfeeding arms and the formula-feeding arms Mother-to-child cumulative transmission rates of HIV-1 for infants in the breastfeeding and formula-feeding arms

\begin{tabular}{|c|c|c|c|c|c|c|c|c|c|c|c|}
\hline \multirow[t]{3}{*}{ Study } & \multirow[t]{3}{*}{ Group } & \multicolumn{10}{|c|}{ Cumulative HIV-1 infection rate (\%) } \\
\hline & & \multirow{2}{*}{$\begin{array}{l}\text { At } \\
\text { birth }\end{array}$} & \multirow[t]{2}{*}{4 weeks } & \multirow[t]{2}{*}{6 weeks } & \multirow{2}{*}{$\begin{array}{c}14 \\
\text { weeks }\end{array}$} & \multicolumn{6}{|c|}{ Months } \\
\hline & & & & & & 3 & 6 & 7 & 12 & 18 & 24 \\
\hline \multirow{2}{*}{$\begin{array}{l}\text { Kenya } \\
\text { (Ndauti et al. }_{2000)^{16}}\end{array}$} & Breastfed (No ART) & 7.0 & --- & 19.9 & 24.5 & $\begin{array}{l}-- \\
-\end{array}$ & 28.0 & --- & 32.3 & --- & 36.7 \\
\hline & Formula-fed (No ART) & 3.1 & --- & 9.7 & 13.2 & $\begin{array}{l}-- \\
-\end{array}$ & 15.9 & --- & 18.2 & --- & 20.5 \\
\hline \multirow{2}{*}{$\begin{array}{l}\text { Botswana } \\
\text { (Thior et al. } \\
2006)^{17}\end{array}$} & $\begin{array}{l}\text { Breastfed + } 6 \text { months } \\
\text { Infant ZDV }\end{array}$ & 3.3 & 4.6 & --- & --- & $\begin{array}{l}-- \\
-\end{array}$ & --- & 9.0 & --- & 9.5 & --- \\
\hline & $\begin{array}{l}\text { Formula }- \text { fed }+1 \\
\text { month Infant ZDV }\end{array}$ & 3.8 & 5.0 & --- & --- & - & --- & 5.6 & --- & 6.0 & --- \\
\hline $\begin{array}{l}\text { Tanzania } \\
\text { (Kilewo et al. } \text { 2009) }\end{array}$ & $\begin{array}{l}\text { Breastfed } \\
\text { ZDV+3TC+NVP } \\
\text { intrapartum and } \\
\text { postpartum }\end{array}$ & --- & --- & 4.1 & --- & $\begin{array}{l}-- \\
-\end{array}$ & 5.0 & --- & 5.8 & 6.0 & --- \\
\hline \multirow{4}{*}{$\begin{array}{l}\text { Abidijan } \\
\text { (Dabis et al. } \\
2005)^{18}\end{array}$} & $\begin{array}{l}\text { Breastfed } \\
\text { ZDV+sdNVP }\end{array}$ & --- & --- & \multirow[t]{2}{*}{6.5} & --- & $\begin{array}{l}-- \\
-\end{array}$ & --- & --- & --- & --- & --- \\
\hline & $\begin{array}{l}\text { Formula-fed } \\
\text { ZDV+sdNVP }\end{array}$ & --- & --- & & --- & - & --- & --- & --- & --- & --- \\
\hline & $\begin{array}{l}\text { Breastfed } \\
\text { ZDV+3TC+sdNVP }\end{array}$ & --- & --- & \multirow[t]{2}{*}{4.7} & --- & $\begin{array}{l}-- \\
-\end{array}$ & --- & --- & --- & --- & --- \\
\hline & $\begin{array}{l}\text { Formula-fed } \\
\text { ZDV+3TC+sdNVP }\end{array}$ & --- & --- & & --- & - & --- & --- & --- & --- & --- \\
\hline
\end{tabular}

\section{KEY:}

ART = antiretroviral therapy, HIV-1 = human immunodeficiency virus type 1, sdNVP= short-dose nevirapine, ZDV = zidovudine, 3TC $=$ lamivudine.

\section{Kilewo et al. 2009 and Dabis et al. 2005}

Two other trials, Kilewo et al. $2009^{11}$ and Dabis et al. $2005,{ }^{18}$ demonstrated the efficacy of cART, which involves three antiretrovirals: ZDV, lamivudine (3TC), and nevirapine (NVP). Kilewo et al. 2009 carried out a non-randomized prospective cohort study where 441 HIV-1 infected pregnant women were given ZDV, 3TC, and NVP. CART started at 34 weeks' gestation and mothers were advised to exclusively breastfeed until 5-6 months, whereby weaning should be commenced. The results concluded that cART, which is a combination of at least three ART drugs, initiated at 34 weeks' gestation and during breastfeeding, resulted in a low HIV transmission rate. ${ }^{19}$ Even though in the breastfeeding group of Thior et al. 2006 the infants were given 6 months of ZDV, the cumulative infection rate at 18 months is lower in Kiwelo et al. 2009 suggesting that HAART given to women is more beneficial than infant prophylaxis. ${ }^{11}$ The Dabis et al. 2005 cohort study included 1144 HIV-1-infected pregnant women and first evaluated the effectiveness of maternal peripartum ZDV regimen followed by a single dose of sdNVP during labour and infant prophylaxis with ZDV and sdNVP in 2001-2002. The trial then evaluated the effectiveness of the same regimen with the addition of maternal 3TC in 2002-2003. Women were advised to either exclusively breastfeed or use breast milk substitutes (formula feeding). The cumulative infection transmission rate at 6 weeks for the group of women receiving $Z D V+s d N V P$ was $6.5 \%$ and $4.7 \%$ for the group receiving $Z D V+3 T C+s d N V P$. Moreover, this trial had also evaluated the effectiveness of using maternal ZDV alone between 1995-2001, concluding a cumulative infection transmission rate of $12.5 \%$. Even though the infection transmission rate was lower in the ZDV+3TC+sdNVP compared with $Z D V+s d N V P$, there was a $72 \%$ reduction in the infection transmission rate in the group of women receiving $Z D V+s d N V P$, as compared with the group receiving ZVD alone. ${ }^{18}$

\section{Discussion}

While several studies of maternal or infant ART prophylaxis during breastfeeding have shown 
significant reductions in the cumulative HIV-1 infection transmission rate, postnatal transmission continues to occur, regardless of optimal treatment. Therefore, the development of strategies and the understanding of the mechanism of transmission of the virus will help to prevent HIV transmission via breastfeeding. For preventative strategies to be implemented, however, it is important to understand the reasons for continued postnatal infection, therefore this paper will aim to discuss the mechanisms and risk factors of breast milk transmission (summarized in table 3 ).

Table 3: Maternal factors associated with the transmission of HIV-1 through breastfeeding. ${ }^{20,21}$

- Feeding method

- Breast health - subclinical or clinical mastitis, abscess, cracked nipples

- RNA viral load in plasma

- RNA viral load in breast milk

- CD4+ cell count

- Maternal nutritional status

- Maternal seroconversion

\section{Maternal factors}

Feeding method

The type of infant feeding influences MTCT rates significantly, regardless of ART mothers may be receiving. Exclusive breastfeeding for up to 6 months is associated with approximately a three- to four-fold decreased risk of postnatal transmission of HIV compared with mixed feeding or early weaning. ${ }^{3}$

If the conditions for exclusive replacement feeding are present, then breastfeeding should be avoided. In the ZVITAMBO study in Zimbabwe, the reported rates of postnatal HIV transmission at 6 weeks were $5.1,6.7$, and 10.5 infections per 100 child-years of breastfeeding for infants who were exclusively breastfed, predominantly breastfed, and mixed breast fed respectively. ${ }^{22}$ Reasons for the increased protection provided by exclusive breastfeeding are incompletely understood. Even though HIV transmission occurs with breastfeeding, not breastfeeding also carries other significant health risks: formula feeding and mixed feeding can increase the risk of infant morbidities such as diarrhoea and respiratory infections. ${ }^{5}$

\section{Breast health}

Furthermore, mixed breastfeeding is a significant risk factor for HIV transmission as the temporary gaps in breastfeeding cause milk stasis in the breast and, as a consequence of this, breast engorgement and risk of mastitis follow. ${ }^{22}$ Mastitis, classified as clinical or subclinical, is an inflammatory process occurring in the breast, whereby paracellular pathways between the mammary alveolar cells dilate, which results in an infiltration of inflammatory cells and extracellular fluid into the milk. Consequently, the presence of the plasma components and inflammatory cells, such as HIV-1 infected lymphocytes, in breast milk can cause the transmission risk to increase. ${ }^{23,24}$ It is thought that, due to = immune activation in the breast, activated cells induce viral replication in breast epithelium and subsequently activate infant enterocytes. ${ }^{25}$ Although clinical mastitis is rare, subclinical mastitis accounts for approximately $50 \%$ of all HIV transmission associated with breastfeeding; it has no clinical symptoms, but it is associated with an increase in milk sodium or potassium and inflammatory cytokines. This abnormal increase in sodium and potassium results from disrupted cell membranes, which also contribute to greater leakage of HIV from plasma to breast milk. ${ }^{22,25}$ A study in Malawi investigating the risk factors for vertical transmission of HIV-1 via breastfeeding found elevated sodium levels consistent with mastitis was present in $16.4 \%$ of HIV-1-infected women. Moreover, elevated breast milk sodium concentration was associated with significantly fewer CD4+ lymphocytes and significantly higher plasma and breast milk HIV-1 load (median HIV-1 load 920 copies/mL versus undetectable $[<200$ copies $/ \mathrm{mL}]$ ), which in turn was associated with an increased vertical transmission rate of HIV-1 at 6 weeks and 12 months compared with those women with a normal sodium range. ${ }^{23}$

RNA and DNA viral load in plasma and breast milk Furthermore, the roles of cell-free (RNA) and cellassociated (DNA) HIV-1 in breast milk transmission remains poorly understood. In an HIV-infected mother, both cell-free and cell-associated HIV-1 are found in beast milk; the virus could either be produced in the systemic compartment before entering the breast compartment or locally in infected lymphocytes. ${ }^{26}$ It has been suggested that increased levels of both cell-free virus and cellassociated virus in maternal plasma and breast milk are linked to an increased risk of transmission. ${ }^{27} \mathrm{~A}$ case-control study in South Africa investigated the relationship between cell-free and cell-associated HIV-1 in breast milk and the potential risk of postnatal transmission at 6 weeks and 6 months. The study included 36 mothers as cases who had 
transmitted HIV-1 to their infant through breastfeeding, and 36 mothers as controls who were non-transmitting HIV-1 infected. The study concluded that postnatal HIV-1 transmission was positively correlated with both cell-free and cellassociated virus levels in breast milk; transmission was most likely with cell-associated virus levels per $\mathrm{mL}$ than cell-free virus at 6 weeks. In addition, transmitting mothers were more likely to have a higher plasma viral load ( $p<0.001$ ) and a lower antenatal CD4 cell count $(p<0.001)$. In comparison to mothers with an antenatal CD4 count of minimum 500 cells $/ \mathrm{mm}^{3}$, mothers with a CD4 count below 500 cells $/ \mathrm{mm}^{3}$ had a significantly higher $\log _{10}$ cell-free and cell-associated virus levels in breast milk.

There are suggestions that antiretroviral treatment has different effects on cell-free and cell-associated virus in breast milk. Results from two independent RCTs suggested that ART (either short-course ZDV, sdNVP, combined ZDV/sdNVP, or short-course HAART) given prior to or post-delivery significantly suppressed cell-free HIV-1 but not cell-associated HIV-1 loads in breast milk. ${ }^{8,28}$ Therefore, since cellassociated HIV-1 virus in breast milk is not affected by maternal ART, this might account for the remaining HIV-1 transmission during breastfeeding.

\section{Maternal nutritional status}

Maternal nutritional status can also influence the risk of HIV transmission via breastfeeding. Vitamin A deficiency is a highly prevalent nutritional deficiency that affects approximately 19 million pregnant women. ${ }^{29}$ Vitamin $A$ is essential for the mother and the development of the fetus. Its main role is in strengthening the immune system's defence against infection via the differentiation of immune cells such as lymphocytes. ${ }^{29}$ Early observational trials had suggested an association between low serum vitamin A levels and increased MTCT of HIV. In Malawi, investigation of 338 HIV-infected mothers found those with a vitamin A concentration of less than $0.70 \mu \mathrm{mol} / \mathrm{L}$ had a MTCT transmission rate of $32.4 \%$ in comparison with $7.2 \%$ among mothers with a vitamin $A$ concentration of greater than or equal to $1.40 \mu \mathrm{mol} / \mathrm{L}(p<0.0001){ }^{30}$

Observational data led to the implementation of trials investigating the efficacy of vitamin supplement on the prevention of MTCT. A metaanalysis of three RCTs concluded that vitamin A supplementation in HIV-positive breastfeeding women has no significant effect on MTCT of HIV; combined risk ratio (RR) of 1.05, $(p=0.2)$. However, one further trial concluded a significant increase in MTCT rates and an increase in transmission of HIV during breastfeeding and vitamin $A$ supplementation, with a RR $1.35(p=0.009) .{ }^{29,31}$

\section{Infant factors}

There are also infant factors that contribute to HIV1 transmission. For a breastfeeding infant, the portal of entry of breast milk is the mouth. However various mucosal surfaces are important sites through which HIV-1 infected beast milk can enter; these include the oral mucosa, tonsillar tissue, and gastrointestinal mucosa. ${ }^{8}$ The integrity of the gastrointestinal mucosal surfaces is important in the transmission of HIV-1 because it is the most likely site at which transmission occurs following the ingestion of HIVinfected breast milk. If the mucosal surfaces of the intestine or mouth are damaged, e.g. in cases such as oral thrush, with breaks in the intestinal epithelial cell layer, the risk of HIV-1 transmission increases. Additionally, cell-associated or cell-free HIV-1 has the potential to cross the submucosa once the virus attaches itself to immature dendritic cells of the gut. Once attached, the cells then transport the antigen to the enterocytes or $M$ cells that are specialized epithelial cells located in the Peyer's patches in the intestinal mucosa. ${ }^{5,21}$

\section{Limitations}

A major limitation in this literature review is that the studies are of diverse design. The majority of studies are RCT but there are also observational and cohort studies. This is a limitation as the type of study has an impact on the quality of the results; the MTCT rates from a RCT would be more reliable due to the rigorous control of the trial. Although rigorous control of breastfeeding regimens has proven benefits to infant health, it is very difficult to maintain in day-to-day life outside of trials, and therefore lacks external validity. Moreover, the trials may be underestimating the magnitude of the problem. Sample size differed between studies with the number of participants ranging from 425-1200 women. This has the potential to mislead, as the interpretation of MTCT rate is based on the sample size of a particular study and, if this varies widely between studies, the comparison of MTCT between studies may not be reliable. There may be an overexaggeration of the results in a small study producing statistically significant results.

A major limitation is the use of different maternal and infant prophylaxis ART regimens and the 
duration of treatment. The different combinations of ART between the mothers and the infants meant that there was uncertainty in evaluating the results and establishing whether a correct cause-effect relation exists between the different types of ART and the impact on MTCT rates of HIV-1 in breastfeeding infants.

\section{Conclusion}

Breastfeeding holds great significance for infants and is an effective feeding option for reducing the risk of childhood morbidity and mortality. Since HIV1 can be transmitted via breast milk, prevention of MTCT of HIV-1 through breastfeeding remains a pressing public health challenge. In resource-poor countries, mothers face a dilemma as to which feeding option they should use for their infant; despite WHO's recommendation, mixed feeding is a common practice which results in an indirect increase in transmission rates due to the increased risk of mothers obtaining mastitis. Moreover, the use of formula milk appears to decrease the rate of postnatal HIV-1 transmission, however it increases morbidity and mortality from other illnesses such as respiratory and diarrheal infections. Therefore, from the several studies mentioned in this review, it can be seen that there are many possible reasons as to why postnatal HIV-1 transmissions continue to occur, despite optimal antiretroviral treatment. If these risk factors are identified and further investigated, actions can be taken in reducing them, which may significantly decrease the risk of MTC HIV-1 transmission.
What is known already:

- Transmission of HIV is known to occur through breastfeeding.

- HAART, together with elective caesarean section and avoidance of breastfeeding, has reduced the rate of MTCT of HIV to below $2 \%$.
What this study adds/ highlights:

- This study evaluates and highlights the significant differences between the HIV-1 transmission rates between breastfeeding and formula feeding.

- This study recognizes the different causative factors that may contribute to the increased risk of HIV-1 transmission through breastfeeding.

- This study evaluates the impact and efficacy of antiretroviral prophylaxis for mothers who breastfeed by comparing mother-to-child transmission rates. 


\section{References}

1. World Health Organization. New Guidance on Prevention of Mother-to-Child Transmission of HIV and Infant Feeding in the Context of HIV. World Health Organization website. 20 July 2010. http://www.who.int/hiv/pub/mtct/PMTCTfactsheet/en/ (accessed 1 July 2015).

2. Oddy WH, Sly PD, de Klerk NH, Landau LI, Kendall GE, Holt PG et al. Breast feeding and respiratory morbidity in infancy: a birth cohort study, Arch Dis Child. 2003;88(3):224-8. doi: 10.1136/adc.88.3.224.

3. World Health Organization. Guidelines on HIV and Infant Feeding 2010: Principles and Recommendations for Infant Feeding in the Context of HIV and a Summary of Evidence. Geneva, Switzerland: World Health Organization; 2010. http://whqlibdoc.who.int/publications/2010/9789241599535_eng.pdf?ua=1 (accessed 17 February 2014).

4. World Health Organization. Treatment of Children Living with HIV. World Health Organization website. http://www.who.int/hiv/topics/paediatric/en/ (accessed 17 February 2014).

5. World Health Organization. HIV Transmission Through Breastfeeding: A Review of Available Evidence. Geneva, Switzerland: World Health Organization; 2007. http://www.who.int/maternal_child_adolescent/documents/9789241596596/en/ (accessed 17 February 2014).

6. Read JS; American Academy of Pediatrics Committee on Pediatric AIDS. Human milk, breastfeeding, and transmission of human immunodeficiency virus type 1 in the United States. Pediatrics. 2003;112(5):1196-205.

7. World Health Organization. Antiretroviral Therapy (ART) Coverage Among all Age Groups. World Health Organization website. http://www.who.int/gho/hiv/epidemic_response/ART_text/en/ (accessed 17 February 2014).

8. Shetty AK, Maldonado Y. Antiretroviral drugs to prevent mother-to-child transmission of HIV during breastfeeding. Curr HIV Res. 2013;11(2):102-25. doi: 10.2174/1570162X11311020004.

9. Palombi L, Marazzib MC, Voetbergc A, Magid NA.Treatment acceleration program and the experience of the DREAM program in prevention of mother-to-child transmission of HIV. AIDS 2007; 21(4): S65-S71.

10. Thomas TK, Masaba R, Borkowf CB, Ndivo R, Zeh C, Misore A, et al. (2011). Triple-Antiretroviral Prophylaxis to Prevent Mother-To-Child HIV Transmission through Breastfeeding-The Kisumu Breastfeeding Study, Kenya. PLoS Med 8(3): e100101

11. Kilewo C, Karlsson K, Ngarina M, Massawe A, Lyamuya E, Swai A et al. Prevention of Mother-to-Child Transmission of HIV1 Through Breastfeeding by Treating Mothers With Triple Antiretroviral Therapy in Dar es Salaam, Tanzania: The Mitra Plus Study. J Acquir Immunw Defic Syndr 2009; 52 (3): 406-416

12. Peltier $C$, Ndayisaba G, Lepage $P$, Griensven J, Leroy $V$, Omes $C$ et al. Breastfeeding with maternal antiretroviral therapy or formula feeding to prevent HIV postnatal mother-to-child transmission in Rwanda. AIDS 2009; 23 (18): 2415-2423

13. The Kesho Bora Study Group. Triple antiretroviral compared with zidovudine and single-dose nevirapine prophylaxis during pregnancy and breastfeeding for prevention of mother-to-child transmission of HIV-1. The Lancet 2011; 11 (3): 171-180

14. R.L. Shapiro, M.D. Hughes, A. Ogwu, D. Kitch, S. Lockman, C. Moffat et al. Antiretroviral Regimens in Pregnancy and Breast-Feeding in Botswana. The New England Journal of Medicine 2010; 362:2282-2294

15. Jamieson D.J, Chasela C.S,Hudgens M.G, King C.C, Kourtis A.P, Kayira D et al. Maternal and infant antiretroviral regimens to prevent postnatal HIV-1 transmission: 48-week follow-up of the BAN randomised controlled trial. The Lancet 2012; 379(9835): 2449-2458

16. Nduati R, John G, Ngacha D M, Richardson B, Overbaugh J, Mwatha A et al. Effect of Breast-feeding and Formula Feeding on Transmission of HIV-1. JAMA 2000 Mar; 283(9):1167-74. doi:10.1001/jama.283.9.1167.

17. Thior I, Lockman S, Smeaton LM, Shapiro RL, Wester C, Heymann SJ et al. Breast-feeding Plus Infant Zidovudine Prophylaxis for 6 Months vs Formula Feeding Plus Infant Zidovudine for 1 Month to Reduce Mother-to-Child HIV Transmission in Botswana. JAMA 2006 Aug 16; 296(7):794-805. doi:10.1001/jama.296.7.794.

18. Dabis F, Bequet L, Ekouevi D K, Viho I, Rouet F, Haro A et al. Field efficacy of Zidovudine, lamivudine and single-dose Nevirapine to prevent peripartum HIV transmission. AIDS 2005 Feb 18;19(3):309-18.

19. World Health Organization. Antiretroviral Therapy. http://www.who.int/topics/antiretroviral_therapy/en/ (Accessed 16 March 2014)

20. UNICEF. HIV and Infant Feeding. http://www.unicef.org/programme/breastfeeding/hiv.htm. [accessed 18 March 2014].

21. UNICEF, UNAIDS, WHO. A Review of HIV transmission through breastfeeding. 1998. http://www.unaids.org/en/media/unaids/contentassets/dataimport/publications/irc-pub03/jc180-hiv-infantfeeding3_en.pdf. [accessed 24 March 2014].

22. Lunney K M, lliff P, Mutasa K, Ntozini R, Magder L S, Moulton L H et al. Associations between Breast Milk Viral Load, Mastitis, Exclusive Breast- Feeding, and Postnatal Transmission of HIV. Oxford Journals-Clinical Infectious Diseases 2010; 50 (5): $762-769$

23. Semba RD, Kumwenda N, Hoover DR, Taha TE, Quinn TC, Mtimavalye L, et al. Human immunodeficiency virus load in breast milk, mastitis, and mother-to-child transmission of human immunodeficiency virus type 1. J Infect Dis. 1999;180(1):93-98. doi: 10.1086/314854.

24. British Medical Journal Best Practice. Mastitis and Breast Abscess. http://bestpractice.bmj.com/bestpractice/monograph/1084/basics/pathophysiology.html (Accessed 14 April 2014)

25. Michie $C$ A. Breast feeding and the risks of viral transmission. Arch Dis Child 2001; 84: 381-382

26. Becquart $P$, Chomont $N$, Roques $P$, Ayouba $A$, Kazatchkine $M D, B e$ lec $L$ et al. Compartmentalization of HIV-1 between Breast Milk and Blood of HIV-Infected Mothers. Virology 2002; 300: 109-117 
27. Ndirangu J, Viljoen J, Bland R M, Danaviah S, Thorne C, Perre P Vde et al. Cell-Free (RNA) and Cell-Associated (DNA) HIV1 and Postnatal Transmission through Breast-feeding. PLoS ONE 2012; 7 (12)

28. Lehman D A, Chung M H, John-Stewart G C, Richardson B A, Kiarie J, Kinuthia J et al. HIV-1 persists in breast milk cells despite antiretroviral treatment to prevent mother-to-child transmission. AIDS 2008; 22 (12): 1475-85

29. World Health Organization. Guideline: Vitamin A Supplementation in Pregnancy for Reducing the Risk of Mother-to-Child Transmission of HIV. Geneva, Switzerland: World Health Organization; 2011. http://apps.who.int/iris/bitstream/10665/44627/1/9789241501804_eng.pdf?ua=1 (accessed 18 April 2014).

30. Semba RD, Miotti PG, Chiphangwi JD, Saah AJ, Canner JK, Dallabetta GA, et al. Maternal vitamin A deficiency and motherto-child transmission of HIV-1. Lancet. 1994;343(8913):1593-7. doi: 10.1016/S0140-6736(94)93056-2.

31. Mills EJ, Wu P, Seely D, Guyatt GH. Vitamin supplementation for prevention of mother-to-child transmission of HIV and pre-term delivery: a systematic review of randomized trial including more than 2800 women. AIDS Res Ther. 2005;2(1):4. doi: 10.1186/1742-6405-2-4

1. 